\title{
Sugar tax drives make promising start around the world
}

$\mathrm{V}$ arious sugar tax policies appear to be making a positive impact on reducing consumption of sugary drinks around the world and the impact that has on dental health.

A study ${ }^{1}$ carried out by researchers at the University of York published in PLOS Medicine on 3 July 2018 looked at the impact of the sugar tax introduced in Chile in 2014.

The researchers, from the University's Centre for Health Economics, found the tax to be effective in reducing the consumption of sugary drinks, but it might not be enough to reduce socioeconomic inequalities in diet-related health.

Chile's sugar tax targeted non-alcoholic beverages to which colourants, flavourings or sweeteners have been added.

For beverages with an added sugar concentration of $6.25 \mathrm{~g}$ per $100 \mathrm{ml}$ or more, the existing tax was increased from $13 \%$ to $18 \%$, while for those below this threshold, the tax was reduced from $13 \%$ to $10 \%$.

The researchers from York, in collaboration with colleagues from Hitotsubashi University, Tokyo, The University of Chile, Santiago, and the Luxembourg Institute for Socio-economic Research, Luxembourg, analysed household grocery purchasing data from Chile for three years before the tax was introduced and for one year afterwards.

The study found an overall $21.6 \%$ decrease in the monthly purchased volume of the higher taxed, sugary soft drinks.

Among middle and high socioeconomic groups, the monthly purchased volume fell by $16 \%$ and $31 \%$, respectively. There was a $12 \%$ reduction in purchase volume for the low socioeconomic group.

However, this was statistically insignificant. By contrast, the volume of non-sugary soft drinks, for which the tax rate had been decreased, showed no increase in purchased volume for any socioeconomic groups.

Marc Suhrcke, Professor of Global Health Economics at the University of York said: 'The results suggest that the Chilean tax policy may have been effective in reducing consumption of sugary drinks, though not necessarily to reduce socioeconomic inequalities in diet-related health.

'Further evaluations are needed to analyse the policy effect on purchasing of soft drinks in the long run as well as to evaluate the impact on health outcomes.'

Professor Cuadrado from the University of Chile added: 'Our results suggest an overall reduction of sugar consumption after the implementation of the tax in Chile. From a public health perspective, even a small reduction in sugar intake at the population level could lead to significant health gains.

'Other countries may take heart from our findings, in that it indicates that the tax incentive may not need to be huge to have impact.'
In the UK, a sugar tax on soft drinks known as the soft drinks industry levy - was introduced in April 2018, and as soon as former Chancellor George Osborne announced in 2016 that it would be implemented, drinks manufacturers started altering their formulations so some drinks contained less sugar.

Any money raised from the tax is to be used to generate grants for investment in children's exercise and healthy eating, and forecasted direct tax receipts from the levy have been reduced from the original prediction of $£ 500$ million in 2018 - 19 to a projected $£ 275$ million, due to manufacturers making changes to their formulations to avoid paying the tax.

This comes as Public Health England (PHE) recently warned that children in England had already consumed more than a year's worth of sugar by the start of June.

Children aged four to ten years should have no more than the equivalent of five to six cubes of sugar each day, but were consuming, on average, 13 cubes, said PHE, according to its calculations, which suggested that children were on track to consume around 4,800 cubes

\section{'Children aged 4 to 10 should have no more than the equivalent of $5-6$ cubes of sugar each day...'}

of sugar by the end of the year.

Dr Alison Tedstone, Chief Nutritionist at PHE said: 'We're barely halfway through the year and already children have consumed far more sugar than is healthy - it's no surprise this is contributing to an obesity crisis.

'Snacks and drinks are adding unnecessary sugar to children's diets without us even noticing. Swapping to lower or no-added-sugar alternatives is something all parents can work towards.'

PHE said it was working with the food industry to cut $20 \%$ of sugar from the foods children consume most by 2020 , while sugar reduction guidelines for juice and milk-based drinks outside the scope of the Soft Drinks Industry Levy are to be achieved by mid-2021.

Meanwhile, in Mexico and Philadelphia in the US, sugar tax policies have also led to changes in purchasing behaviour.

Mexico's $10 \%$ tax on sugar-sweetened beverages implemented in January 2014 is said to have led to a 5.5\% drop in sugary drinks purchases by the end of that year and a further 9.7\% fall in sales in 2015, yielding an average reduction of $7.6 \%$ over the study two-year period.

These findings came from a study ${ }^{2}$ carried out by researchers from the National Institute of Public Health, in Cuernavaca, Mexico, and the University of North Carolina, USA, published in March 2017 in Health Affairs journal. 
In addition, the largest fall in sales was noted amongst the most socioeconomically disadvantaged parts of the population, although the soft drinks industry in the country has since claimed that the policy has been ineffective in reducing obesity and only effective in raising product prices and tax collection.

Success has also been seen in Philadelphia in the USA, where researchers from the city's Drexel University analysed the effects of Philadelphia's sugary drink tax implemented in January 2017-which increased the cost of sugary drinks by as much as $20 \%$.

For their study ${ }^{3}$ published on 12 April 122018 in the American Journal of Preventive Medicine, the researchers asked 899 adults in Philadelphia about their sugar-sweetened beverage habits before and after the tax was launched.

Results were compared with 878 people living in three other cities Trenton, New Jersey; Camden, New Jersey; and Wilmington, Delaware - and showed that people living in Philadelphia were $40 \%$ less likely to report consuming sugary drinks every day after the tax policy began, and $64 \%$ less likely to drink energy drinks. In addition, Philadelphia people were $58 \%$ more likely to drink bottled water daily.

Commenting on the research about Chile, Dr Kara Gray-Burrows, a psychologist working as a researcher at the School of Dentistry, University of Leeds, said: 'There seems to have been a significant decrease [in sales of sugary drinks] particularly in the higher socio-
The Lancet Taskforce on NCDs and Economics, which collected the series of papers, said the analysis of data from 13 countries - Chile, Guatemala, Panama, Nicaragua, Albania, Poland, Turkey, Tajikistan, Tanzania, Niger, Nigeria, India and Timor-Leste - gave strong evidence that taxes on unhealthy products had the potential to produce significant health gains among the poorest in society who were disproportionately affected by NCDs.

\section{'People often think they're buying something healthy [when they buy these drinks] and they're not...'}

Dr Rachel Nugent, Chair of The Lancet Taskforce, said at the time: 'Non-communicable diseases are a major cause and consequence of poverty worldwide.

'Responding to this challenge means big investments to improve healthcare systems worldwide, but there are immediate and effective tools at our disposal. Taxes on unhealthy products can produce major health gains, and the evidence shows these can be implemented fairly,
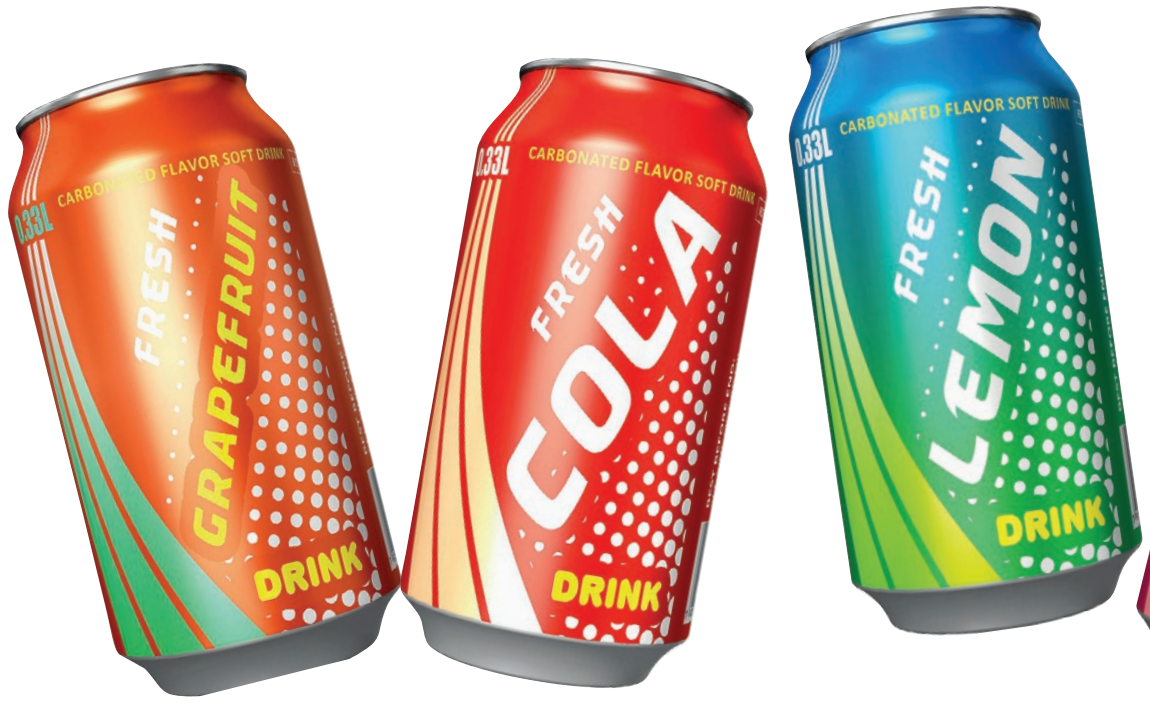
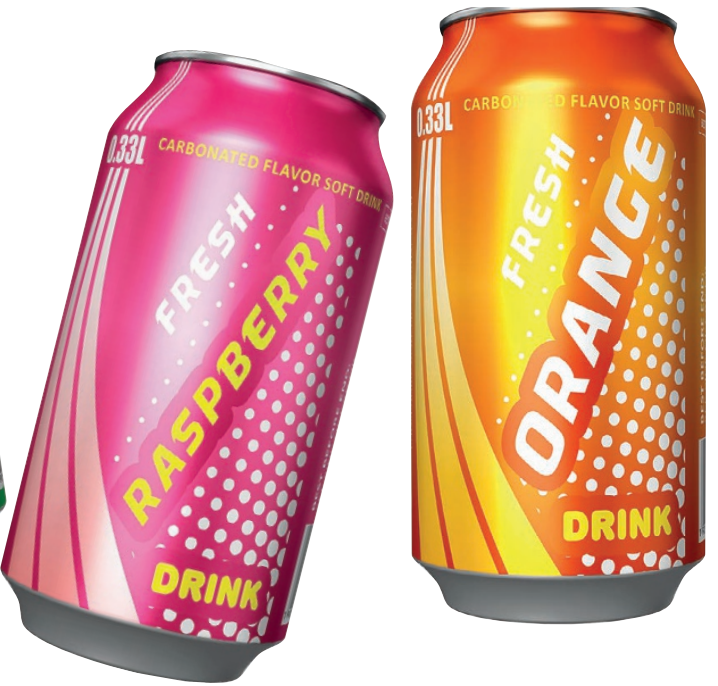

economic status families, but we need to see how it goes over time.

'These things do not happen quickly. With smoking, it took a long time for smoking to become denormalised. It's very much a top-down approach and these things work best when there's a match up between top-down and grass-roots, community support for change as well.

'The UK sugar tax raises the level of awareness as a first step. A lot of the difficulty with these drinks is, sometimes, a person thinks they're buying something healthy and they're not. There's still work to be done because sometimes, it's not always obvious where the sugar is.'

Collectively, taxing unhealthy products seems to work and research ${ }^{4}$ published in The Lancet on 4 April 2018 suggested that various international policies of taxing the likes of soft drinks, alcohol and tobacco were effective in tackling non-communicable diseases (NCDs).

In the global analysis of evidence on expenditure, behaviour and socioeconomic status, various related studies concluded that taxes on these unhealthy products were a powerful response to rising rates of chronic diseases. without disproportionately harming the poorest in society'.

The issue is clearly a hot topic and the British Dental Association is set to hold a large 'sugar summit' event in November at which sugar, nutrition and dental experts will discuss the issue as well as take part in debate on what can be done to tackle sugar consumption beyond the tax approach.

1. Nakamura, R, Mirelman, A J, Cuadrado, C, Silva-Illanes, N, Dunstan, J, and Suhrcke, M PLOS Medicine 15(7): e1002596.D0I:10.1371/journal.pmed.1002596. Evaluating the 2014 sugar-sweetened beverage tax in Chile: An observational study in urban areas. http://journals. plos.org/plosmedicine/article?id=10.1371/journal.pmed.1002596.

2. Colchero M A, Rivera-Dommarco J, Popkin B M, and Ng S W. In Mexico, Evidence Of Sustained Consumer Response Two Years After Implementing A Sugar-Sweetened Beverage Tax. Health Affairs DOI:10.1377/hlthaff.2016.1231. https://www.healthaffairs. org/doi/full/10.1377/hlthaff.2016.1231.

3. Zhong Y, Auchincloss A H, Lee B K, Kanter G P. The Short-Term Impacts of the Philadelphia Beverage Tax on Beverage Consumption. American Journal of Preventive Medicine , Volume 55, Issue 1, 26 - 34. D0I:10.1016/j.amepre.2018.02.017. https://www. ajpmonline.org/article/S0749-3797(18)31600-3/fulltext.

4. The Lancet Taskforce on NCDs and economics. The Lancet 2018; 10128: 1331-1454. https://www.thelancet.com/series/Taskforce-NCDs-and-economics. 